\title{
An aggressive and expanded phenotype in a kindred with a C.57deIG SDHD mutation
}

\author{
Celina Caetano ${ }^{1}$, Jennifer Stroop², Faripour Forouhar ${ }^{3}$, Andrea Orsey 4,5 and \\ Carl Malchoff(1)
}

1Division of Endocrinology and Metabolism and the Endocrine Neoplasia Program of the Neag Cancer Center, 2Department of Genetics and Developmental Biology, ${ }^{3}$ Department of Pathology and Laboratory Medicine, UCONN Health, Farmington, Connecticut, USA, ${ }^{4}$ Department of Pediatrics, University of Connecticut School of Medicine, Farmington, Connecticut, USA, and ${ }^{5}$ Division of Pediatric Hematology/Oncology, Connecticut Children's Medical Center, Hartford, Connecticut, USA

Correspondence should be addressed to C Malchoff

Email

malchoff@uchc.edu

\section{Summary}

Familial paraganglioma syndrome type 1 (PGL-1) is maternally imprinted, caused by SDHD mutations on the paternally inherited allele, and presents with paragangliomas and pheochromocytomas that are usually benign. We describe a kindred with a germline c.57delG SDHD mutation that demonstrates an aggressive and possibly expanded phenotype. Eight individuals across four generations were heterozygous for the c.57delG SDHD mutation. The three with known paternal inheritance were clinically affected. The aggressive phenotype was manifested by a neck paraganglioma with distant metastases, and to a lesser degree a neck paraganglioma infiltrating into local connective tissue and a pheochromocytoma presenting at age $8 \mathrm{y}$. A pulmonary capillary hemangioma may expand the SDHD phenotype. We conclude that the c.57delG SDHD mutation may confer a more aggressive and possibly expanded phenotype than other SDHD mutations.

\section{Learning points:}

- The c.57delG SDHD mutation may confer a more aggressive phenotype than other mutations associated with familial paraganglioma syndrome type 1.

- A capillary hemangioma, a component of other pseudohypoxia states, was observed in the lung of a single member of the c.57delG SDHD kindred.

- This report supports the hypothesis of others that mutations found near the beginning of the SDHD open reading frame are more likely to demonstrate an aggressive phenotype.

\section{Background}

Pseudohypoxia is a state of dysregulated cellular respiration that contributes to the hypoxic phenotype in the absence of hypoxemia. The pseudohypoxia state is caused by germline mutations in $S D H B, S D H D, S D A F 2, S D H C, V H L$, NF1, HIF1/HIF2A, and IDH1/IDH2, and the phenotype is manifested by pheochromocytomas and paragangliomas $(1,2,3)$. SDHD mutations cause the PGL-1 syndrome that is maternally imprinted and presents with sympathetic and parasympathetic paragangliomas of the head, neck, thorax and abdomen, and with pheochromocytomas (4, 5). We describe a kindred with a germline c.57delG SDHD mutation with an aggressive and expanded phenotype.

\section{DNA analysis}

Germline DNA testing of the index subject was performed at Boston University School of Medicine, Center for Human Genetics CLIA approved-laboratory by Sanger 
sequencing. Fluorescence labeled PCR primers in exon flanking regions were used to amplify and sequence $S D H D$ in both directions revealed germline DNA sequencing. Results revealed a c.57delG SDHD mutation (Fig. 1). Nine other related family members underwent similar testing using single-site analysis for the c.57delG mutation at Baylor Genetics/Baylor College of Medicine, and SDHD sequence analysis and deletion/duplication testing at Invitae. A DNA sample from the proband was included as a positive control. Results revealed seven individuals with the same mutation (Fig. 2).

\section{Case presentations}

\section{Index subject (Subject III-1)}

The index subject was a male who presented at age 23 years with bilateral Shamblin III carotid body tumors that measured $2.5 \times 1.3 \times 3.5 \mathrm{~cm}$ on the left and $2.67 \times 1.3 \times 3.9$ $\mathrm{cm}$ on the right. He was treated with surgical debulking followed by external beam radiation.

At age 31 years, he was found to have multiple and diffuse lung metastases that were $<5 \mathrm{~mm}$, confirmed by biopsy, and both were meta-iodobenzylguanidine (MIBG) and ${ }^{111}$ In-pentetreotide avid. These were treated with Gemcitabine, high dose In-111-Octreotide, $100 \mathrm{mCi}$ I-131-MIBG and four cycles of Cytoxan, Vincristine and Dacarbazine. Following these therapies, the metastases have remained stable through the present (50-year-old). Germline DNA analysis described below was performed at age 32 years.

At age 33 years, a $3.8 \mathrm{~cm}$ right pheochromocytoma and $2.6 \mathrm{~cm}$ left pheochromocytoma were identified. Prior to resection, on two separate occasions, the plasma normetanephrine concentration was 16.9 and $14.2 \mathrm{nmol} / \mathrm{L}(\mathrm{nl}<0.9 \mathrm{nmol} / \mathrm{L})$, and the plasma metanephrine concentration was normal. Following bilateral adrenalectomy, the plasma normetanephrine concentration normalized.
At age 34 years, a $0.1 \mathrm{~mm}$ diameter pulmonary capillary hemangioma was found on transtracheal lung biopsy that was performed to evaluate shortness of breath. This diagnosis was confirmed by pathology findings on H\&E staining (Fig. 3A), positive staining with factor A and CD34 (Fig. 3B), and negative staining with S100 and actin. From age 34 years through the present (50-year-old), the serum calcitonin concentration has been repeatedly elevated $($ mean $=20.1 \mathrm{ng} / \mathrm{L} ;$ range $=12-32 ; \mathrm{nl}=0-7.5)$.

Neck MRI scans performed approximately every 18-24 months to confirm stability of size of the neck paragangliomas have not identified any thyroid masses.

\section{Subject III-4}

Subject III-4, the genetically affected sister of the index subject, presented at age 37 years with a Shamblin II right carotid body tumor measuring $2.1 \times 1.7 \times 1.3 \mathrm{~cm}$ with infiltrative growth into adjacent soft tissue, a Shamblin I left carotid body tumor measuring $1.4 \times 1.2 \times 2.4 \mathrm{~cm}$, and a Shamblin I left glomus vagal tumor extending to the base of the skull and measuring $4.1 \times 2.2$ by 1.8 $\mathrm{cm}$. She underwent embolization of the glomus tumor, followed by resection of both the glomus tumor and the carotid body tumors. Although the right carotid body tumor showed low mitotic activity, the infiltrative border composed of ribbon-like cords that invaded the surrounding connective tissue. This invasive disease was treated with external radiation. She is currently being monitored for any progressions of her disease. There has been no recurrence of her neck paragangliomas. Eleven years following radiation, serum calcitonin concentrations have remained normal, and she has not developed a pheochromocytoma.

\section{Subject IV-3}

Subject IV-3, the genetically affected son of the index subject, presented at age 8 years with a $2 \mathrm{~cm}$ right
C. A - G - C - I - C - T- K - I - K - S - Y - I - Y - C - - A - A - W - T - K - C - W - R - T - G - G

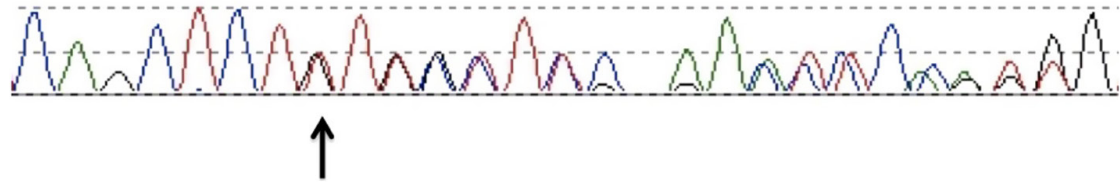

Figure 1

Chromatogram Demonstrating the Heterozygous c.57delG SDHD Mutation of the Index Subject (III-1). Whole blood DNA was sequenced by Sanger sequencing at Boston University School of Medicine, Center for Human Genetics CLIA approved-laboratory. The arrow indicates the c.57delG. The c.57delG SDHD mutation predicts that amino acid 20 is changed from a leucine to cysteine, that the downstream amino acids are changed, and that a new stop codon at amino acid position 66 will end protein translation. 


\section{$\boldsymbol{+}_{\mathrm{c} .57 \mathrm{delG}}$ SDHD mutation}

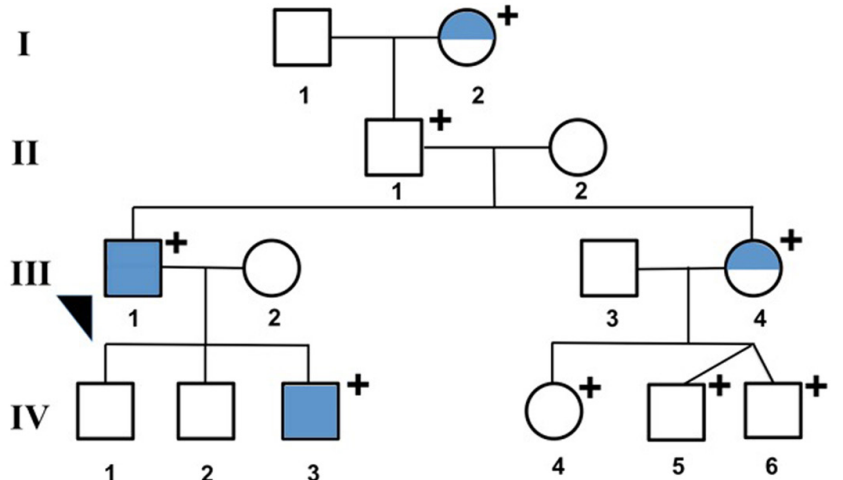

Figure 2

The PGL-1 Kindred Carrying the c.57delG SDHD Mutation. The + indicates that the subject carries the c.57delG SDHD mutation. The arrowhead indicates the index subject (III-1). Filled upper half symbols indicate a head/neck paraganglioma, and filled lower half symbols indicate a pheochromocytoma. Genetic testing was performed on I-2, II-1, III-1, III-4, and all members of generation IV.

pheochromocytoma that was treated with adrenalectomy. At age 20 years, he developed a $1.8 \mathrm{~cm}$ neck mass that enhanced on MRI scan with Gadavist intravenous contrast and is located between the left internal carotid artery and the left internal jugular vein. This is likely a paraganglioma.

He is currently being monitored for any progression of his disease.

\section{Subject I-2}

Subject I-2, the paternal grandmother of the index subject, was a known carrier of the c.57delG SDHD mutation. By history, she had bilateral paragangliomas and lived over 95 years.

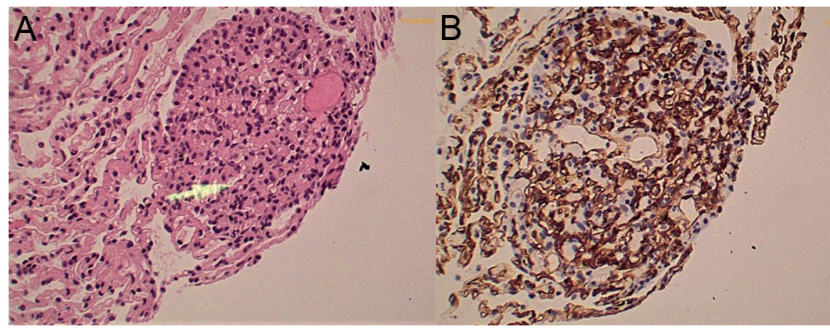

\section{Figure 3}

$\mathrm{H} \& \mathrm{E}, \times 200$; Capillary Hemangioma of the Lung Parenchyma. The arrow points to capillary space and endothelial cell (A). Immunoperoxidase/ CD34, 200; The endothelial marker CD34 is uniformly positive (B).

\section{Discussion}

This report describes a PGL-1 kindred with an aggressive and possibly expanded phenotype caused by a c.57delG SDHD mutation. The c.57delG SDHD mutation predicts that amino acid 20 is changed from a leucine to cysteine, that the downstream amino acids are changed, and that a new stop codon at amino acid position 66 will end protein translation.

The PGL-1 phenotype is generally not aggressive. The risk of malignant paraganglioma is reported to be $<10 \%(6,7)$, the average age of onset is 30.6 years (range from 5 to 60 years) (5), and the prevalence of pheochromocytoma is $29 \%$ (8). In contrast to the expected PGL-1 benign phenotype, this PGL-1 kindred demonstrated unusually aggressive paragangliomas. This is indicated by metastatic disease (III-1) and possibly by the infiltrative neck paraganglioma requiring external radiation and onset of pheochromocytoma at a young age. A review of the literature reveals only one other documentation of the c.57delG SDHD mutation (9, 10). At age 19 years, this individual was evaluated for a stomach gastrointestinal stromal tumor. He also had presumed metastatic paraganglioma to the T8 vertebra, ileum, abdominal masses and liver lesions as indicated by [123I] MIBG uptake $(10,11)$. Therefore, our experience in a single kindred, in combination with the report of another individual, suggests that the c.57delG SDHD mutation effects a more aggressive phenotype than expected for PGL-1.

The findings in this kindred may expand the conventional phenotype of PGL-1. In addition to the usual paragangliomas and pheochromocytomas, the index subject (III-1) had a pulmonary capillary hemangioma. Visceral capillary hemangiomas have not previously been described in PGL-1. However, these are known components of other pseudohypoxia syndromes, including the von Hippel-Lindau Syndrome with retinal and spinal cord hemangiomas, the polycythemia-paragangliomasomatostatinoma syndrome with hepatic hemangiomas, and the Maffucci Syndrome with soft tissue hemangiomas $(2,12,13)$. These disorders are caused by mutations of VHL, HIF1/HIF2A, and IDH1/IDH2, respectively $(2,12,13)$. Pulmonary capillary hemangiomas are exceedingly rare in the general population (14). Therefore, the pulmonary capillary hemangioma may be a novel component of the c.57delG SDHD pseudohypoxia syndrome.

The significance of the elevated serum calcitonin concentration is unknown. Elevated serum calcitonin impacts about $2 \%$ of people with thyroid nodules, 
and is rarely present in other disorders $(15,16)$. It has been reported to be caused by C-cell hyperplasia in PGL-1 $(17,18)$ and by an islet cell tumor in von Hippel-Lindau syndrome (19). C-cells of the thyroid and paragangliomas are both embryological derivatives of neural crest cells, and neuroendocrine tumors are well known to be components of multiple different pseudohypoxia syndromes $(20,21,22)$. We do not know if the hypercalcitoninemia arises from the C-cells or is produced by the paragangliomas. Therefore, the significance of this finding is unknown.

It has been suggested that SDHD nonsense and splicing mutations that are found near the beginning of the open reading frame may predispose to the development of paragangliomas and pheochromocytomas at a younger age than missense mutations throughout the gene (5, $6,23,24)$. The earliest reported onset of PGL-1 was a 5 -year-old female with pheochromocytomas who had a nonsense mutation at the codon predicting amino acid 5 of the SDHD gene (5). Consistent with these observations, the kindred presented here has a frameshift mutation at amino acid 20, and the youngest age of onset is a pheochromocytoma at age 8 years.

It is possible that the aggressive disease and potentially expanded phenotype in this kindred is caused by an unknown modifier gene and is not due entirely to the c.57delG SDHD mutation. It is impossible to exclude this possibility without knowledge of potential PGL modifier genes. However, since the only other individual in the literature with this c.57delG SDHD had aggressive disease, it seems most likely that there is a genotype-phenotype correlation as opposed to the effect of an unknown modifier gene.

\section{Conclusion}

We conclude that the c.57delG SDHD mutation may confer a more aggressive and possibly expanded phenotype than other SDHD mutations.

\section{Declaration of interest}

The authors declare that there is no conflict of interest that could be perceived as prejudicing the impartiality of the research reported.

\section{Funding}

This research did not receive any specific grant from any funding agency in the public, commercial, or not-for-profit sector.

\section{Patient consent}

This study was approved by the Institutional Review Board of the University of Connecticut Health Center. This was a retrospective collection of data, and therefore no consent was required.

\section{Author contribution statement}

$C \mathrm{C}$ and $\mathrm{C} M$ were involved in writing the manuscript. A $O$ and $C M$ were involved in the clinical care of these patients. C C, J S, and C M were involved in collection of clinical data. JS was involved in the the genetic analysis. F F was involved in the pathological analysis of the specimens mentioned. All authors were involved in the final review of the manuscript.

\section{References}

1 Fishbein L, Leshchiner I, Walter V, Danilova L, Robertson AG, Johnson AR, Lichtenberg TM, Murray BA, Ghayee HK, Else T, et al. Comprehensive molecular characterization of pheochromocytoma and paraganglioma. Cancer Cell 201731 181-193. (https://doi. org/10.1016/j.ccell.2017.01.001)

2 Prokopchuk O, Andres S, Becker K, Holzapfel K, Hartmann D \& Friess H. Maffucci syndrome and neoplasms: a case report and review of the literature. BMC Research Notes 20169 126. (https://doi. org/10.1186/s13104-016-1913-x)

3 Vicha A, Musil Z \& Pacak K. Genetics of pheochromocytoma and paraganglioma syndromes: new advances and future treatment options. Current Opinion in Endocrinology, Diabetes, and Obesity 2013 20 186-191. (https://doi.org/10.1097/MED.0b013e32835fcc45).

4 Boedeker CC, Neumann HP, Offergeld C, Maier W, Falcioni M, Berlis A \& Schipper J. Clinical features of paraganglioma syndromes. Skull Base 200919 17-25. (https://doi.org/10.1055/s-0028-1103123)

5 Neumann HP, Pawlu C, Peczkowska M, Bausch B, McWhinney SR, Muresan M, Buchta M, Franke G, Klisch J, Bley TA, et al. Distinct clinical features of paraganglioma syndromes associated with SDHB and SDHD gene mutations. JAMA 2004292 943-951. (https://doi. org/10.1001/jama.292.8.943)

6 Astrom K, Cohen JE, Willett-Brozick JE, Aston CE \& Baysal BE. Altitude is a phenotypic modifier in hereditary paraganglioma type 1: evidence for an oxygen-sensing defect. Human Genetics 2003113 228-237. (https://doi.org/10.1007/s00439-003-0969-6)

7 Else T, Greenberg S \& Fishbein L. Hereditary paragangliomapheochromocytoma syndromes. In GeneReviews((R)). Eds MP Adam, HH Ardinger, RA Pagon, SE Wallace, LJH Bean, K Stephens and A Amemiya. University of Washington, Seattle, WA, 2008.

8 Ricketts CJ, Forman JR, Rattenberry E, Bradshaw N, Lalloo F, Izatt L, Cole TR, Armstrong R, Kumar VK, Morrison PJ, et al. Tumor risks and genotype-phenotype-proteotype analysis in 358 patients with germline mutations in SDHB and SDHD. Human Mutation 201031 41-51. (https://doi.org/10.1002/humu.21136)

9 NM_003002.4(SDHD):c.57del (p.Leu20fs) [Internet]. ClinVar. [cited 17 Jan 2020]. (available at: https://www.ncbi.nlm.nih.gov/clinvar/ variation/6917/)

10 Pasini B, McWhinney SR, Bei T, Matyakhina L, Stergiopoulos S, Muchow M, Boikos SA, Ferrando B, Pacak K, Assie G, et al. Clinical and molecular genetics of patients with the Carney-Stratakis syndrome and germline mutations of the genes coding for the succinate dehydrogenase subunits SDHB, SDHC, and SDHD. European Journal of Human Genetics 2008 16 79-88. (https://doi.org/10.1038/ sj.ejhg.5201904)

11 Ghayee HK, Havekes B, Corssmit EP, Eisenhofer G, Hammes SR, Ahmad Z, Tessnow A, Lazúrová I, Adams KT, Fojo AT, et al. Mediastinal paragangliomas: association with mutations in the succinate dehydrogenase genes and aggressive behavior. Endocrine- 
Related Cancer 200916 291-299. (https://doi.org/10.1677/ERC-080214)

12 Ben-Skowronek I \& Kozaczuk S. Von Hippel-Lindau syndrome. Hormone Research in Paediatrics 201584 145-152. (https://doi. org/10.1159/000431323)

13 Darr R, Nambuba J, Del Rivero J, Janssen I, Merino M, Todorovic M, Balint B, Jochmanova I, Prchal JT, Lechan RM, et al. Novel insights into the polycythemia-paraganglioma-somatostatinoma syndrome. Endocrine-Related Cancer 201623 899-908. (https://doi.org/10.1530/ ERC-16-0231)

14 Shields TW. General Thoracic Surgery, 7th ed. Philadelphia: Wolters Kluwer Health/Lippincott Williams \& Wilkins, 2009.

15 Azizi G, Keller JM, Mayo ML, Piper K, Puett D, Earp KM \& Malchoff CD. Shear wave elastography and afirma gene expression classifier in thyroid nodules with indeterminate cytology: a comparison study. Endocrine 201859 573-584. (https://doi. org/10.1007/s12020-017-1509-9)

16 d'Herbomez M, Caron P, Bauters C, Do Cao C, Schlienger JL, Sapin R, Baldet L, Carnaille B, Wémeau JL \& French Group GTE (Groupe des Tumeurs Endocrines). Reference range of serum calcitonin levels in humans: influence of calcitonin assays, sex, age, and cigarette smoking. European Journal of Endocrinology 2007 157 749-755. (https://doi.org/10.1530/EJE-07-0566)

17 Lima J, Teixeira-Gomes J, Soares P, Maximo V, Honavar M, Williams D \& Sobrinho-Simões M. Germline succinate dehydrogenase subunit D mutation segregating with familial non-RET C cell hyperplasia. Journal of Clinical Endocrinology and Metabolism 200388 4932-4937. (https://doi.org/10.1210/jc.2002-030008).
18 Perren A, Barghorn A, Schmid S, Saremaslani P, Roth J, Heitz PU $\&$ Komminoth P. Absence of somatic SDHD mutations in sporadic neuroendocrine tumors and detection of two germline variants in paraganglioma patients. Oncogene 200221 7605-7608. (https://doi. org/10.1038/sj.onc.1205812).

19 Cornish D, Pont A, Minor D, Coombs JL \& Bennington J. Metastatic islet cell tumor in von Hippel-Lindau disease. American Journal of Medicine 198477 147-150. (https://doi.org/10.1016/00029343(84)90450-9).

20 Cote GJ, Grubbs EG \& Hofmann MC. Thyroid C-cell biology and oncogenic transformation. Recent Results in Cancer Research 2015204 1-39. (https://doi.org/10.1007/978-3-319-22542-5_1)

$21 \mathrm{Hu}$ K \& Persky MS. Treatment of head and neck paragangliomas. Cancer Control 201623 228-241. (https://doi.org/10.1177/107327481 602300306)

22 Kluckova K \& Tennant DA. Metabolic implications of hypoxia and pseudohypoxia in pheochromocytoma and paraganglioma. Cell and Tissue Research 2018372 367-378. (https://doi.org/10.1007/s00441018-2801-6)

23 Benn DE, Gimenez-Roqueplo AP, Reilly JR, Bertherat J, Burgess J, Byth K, Croxson M, Dahia PL, Elston M, Gimm O, et al. Clinical presentation and penetrance of pheochromocytoma/paraganglioma syndromes. Journal of Clinical Endocrinology and Metabolism 200691 827-836. (https://doi.org/10.1210/jc.2005-1862).

24 Pasini B \& Stratakis CA. SDH mutations in tumorigenesis and inherited endocrine tumours: lesson from the phaeochromocytomaparaganglioma syndromes. Journal of Internal Medicine 2009266 19-42. (https://doi.org/10.1111/j.1365-2796.2009.02111.x)

Received in final form 28 January 2021

Accepted 22 February 2021 